\title{
Identification of G-quadruplex sequences in severe acute respiratory syndrome coronavirus 2
}

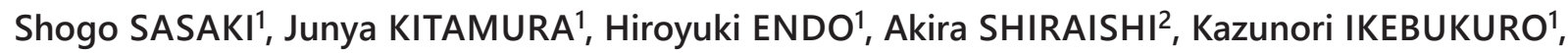 \\ Tetsuya MIZUTANI ${ }^{3}$ and Masayuki TERA ${ }^{1 *}$ \\ 1 Department of Biotechnology and Life Science, Tokyo University of Agriculture and Technology, 2-24-16 Naka-cho, Koganei, Tokyo 184-8588, \\ Japan \\ 2 Bioorganic Research Institute, Suntory Foundation for Life Science, 8-1-1 Seikadai, Seikacho, Soraku, Kyoto 619-0284, Japan \\ 3 Center for Infectious Diseases of Epidemiology and Prevention Research, Tokyo University of Agriculture and Technology, 3-5-8 Saiwai-cho, \\ Fuchu, Tokyo, 183-8509, Japan
}

Key words: G-quadruplexes, anti-viral drug, translation, nucleic acids structure

\section{Introduction}

Anti-viral drugs based on small molecules constitute only a handful of drug classes, including nucleoside analogs, nuclease inhibitors, neuraminidase inhibitors, integrase inhibitors, and retro-transcriptase inhibitors [1]. Combinations of different types of antiviral drugs are effective in overcoming drug-resistant viruses; therefore, antiviral drugs exhibiting novel mechanisms are in high demand.

G4 is a higher-order nucleic acid structure formed by the interaction of guanine bases and hydrogen bonding as the principal driving force in the sequence rule for $\left(\mathrm{G}_{3} \mathrm{~N}_{1-7}\right)_{3} \mathrm{G}_{3}$ (G: guanine, N: any nucleobase) (Fig. 1). G4 is a dynamic structure that undergoes formation and dissociation in vivo. Ribosomes are stalled/arrested at the G4 point of formation, dissociating from mRNA and inhibiting translation [1]. Genomic DNA/RNA G4 inhibits the polymerase elongation reaction and inhibits transcription and replication ${ }^{2}$. Consequently, G4 has attracted much attention as a characteristic higher-order nucleic acid structure and is expected to be a new target for drugs involved in protein expression and replication. In the field of antiviral drug discovery, G4 sequences have been identified in the genomes of several RNA viruses, such as coronaviruses [2], retroviruses [3], and flaviviruses [4]. It has also been reported that both viral growth and viral protein synthesis are inhibited by G4 ligand treatments [5]. Although G4 is also present in host cells, the genome and mRNA are the same sequence in (+) ssRNA viruses, and a G4-targeted drug discovery strategy can inhibit the entire life cycle of viral replication, transcription, and translation. We have developed a G4 ligand of hexaoxazole telomestatin derivatives (6OTDs) and berberine derivatives, which specifically stabilize G4 (Fig. 1c; OTDs [6] and BBR dimer [7]) and launched 6OTD as a potent G4 ligand. Using fluorescent dye-tagged OTD (L1Cy5-7OTD), we identified 2,000 G4-forming sequences using a DNA microarray [8]. Recently, we developed

*Correspondence to: Tera, M.: tera@go.tuat.ac.jp

Received: Aug. 30, 2021; Accepted: Oct. 28, 2021 fluorogenic OTD derivatives that enabled the screening of G4-forming oligonucleotides without any modification [9]. In this study, we identified G4-forming sequences from the severe acute respiratory syndrome coronavirus 2 (SARS-CoV-2) delta variant (B.1.617.2) genome based on our previous microarray results.

\section{Material and Methods}

All DNA (SC-1: ATAAGGGTATTAAAATACAAGAGGGTGTGGTTGATTATGG and SC-2: GGGTCAGGGTTTAAATGGTTACACTGTAGAGG) and RNA (SC-1r: AUAAGGGUAUUAAAAUACAAGAGGGUGUGGUUGAUUAUGG and SC-2r: GGGUCAGGGUUUAAAUGGUUACACUGUAGAGG) oligonucleotides were purchased from Integrated DNA Technologies as HPLC purification grade and used without further purification. All buffers and reagents were purchased from Sigma-Aldrich (St. Louis, MO, USA), Wako Chemicals (FujiFilm Wako Chemicals, Osaka, Japan), or Tokyo Chemical Industry (Tokyo, Japan) (molecular biology grade).

\section{UV measurement}

Oligonucleotides were dissolved in $10 \mathrm{mM}$ lithium cacodylate buffer ( $\mathrm{pH} 7.4)$ containing $\mathrm{KCl}(0,100$, or 1,000 $\mathrm{mM}$ ) to give a final concentration of $10 \mu \mathrm{M}$. The samples were denatured at $95^{\circ} \mathrm{C}$ for $5 \mathrm{~min}$, followed by slow cooling to $25^{\circ} \mathrm{C}$. UV spectra were recorded on a V-630 spectropolarimeter (JASCO, Tokyo, Japan) using a quartz cell with an optical path length of $10 \mathrm{~mm}$ (scanning speed: $100 \mathrm{~nm} /$ min, wavelength range: $280-330 \mathrm{~nm}$ ) at $25^{\circ} \mathrm{C}$. Isothermal difference spectra (IDS) were obtained by subtracting the UV spectra without $\mathrm{KCl}$ from those with $100 \mathrm{mM}$ or 1,000 $\mathrm{mM} \mathrm{KCl}$.

\section{In vitro translation}

In vitro translation was performed using Purefrex (GeneFrontier, Kashiwa, Japan). Each template DNA was constructed from a plasmid vector carrying the enhanced green fluorescent protein (EGFP) gene by two-step PCR, and the concentration of the PCR products was adjusted 


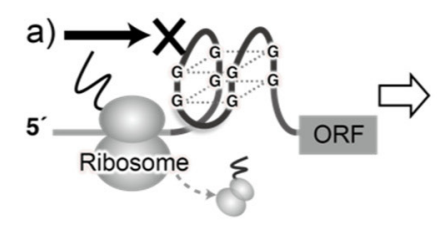

b) G G G

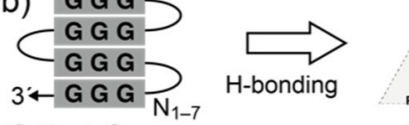

$\left(\mathrm{G}_{3} \mathrm{~N}_{1-7}\right)_{3} \mathrm{G}_{3}$ :

Putative $\mathrm{G} 4$ sequences

$\rightarrow$ Many exceptions reported
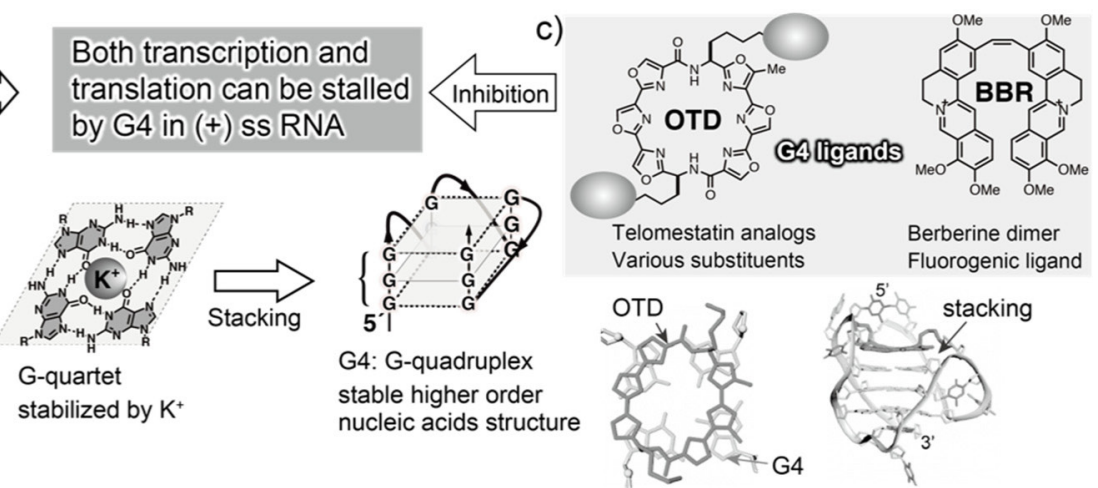

Fig. 1. a) Scheme for stalling ribosomes by G4. G4 ligands can inhibit not only translation, but also transcription and replication activities, because (+)ssRNA viruses have the same mRNA and genome sequences. $\mathbf{b})$ The schematic structures of putative G4 sequences, G-quartet, and G4. c) Original G4 ligands and the manner of binding with G4, shown and proven by NMR.

a)

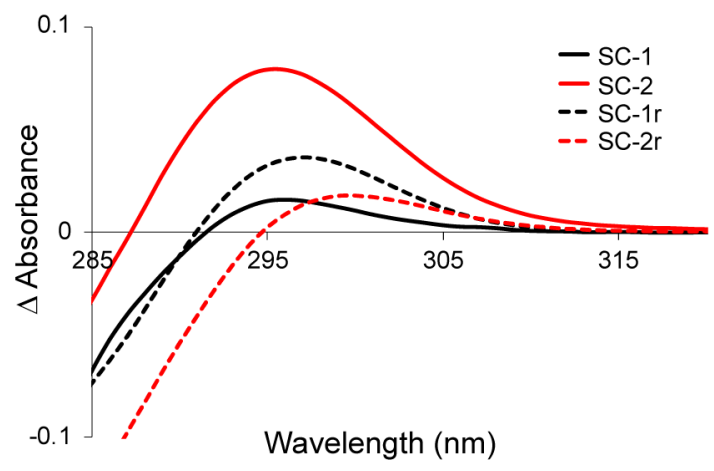

b)

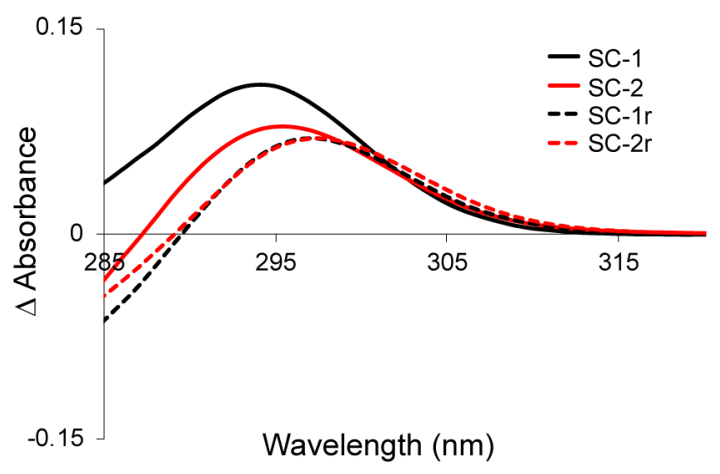

Fig. 2. Isothermal difference spectra analysis of $10 \mu \mathrm{M}$ oligonucleotides of SC-1 (solid black), SC-2 (solid red), SC-1r (dashed black), and SC-2r (dashed red) in lithium cacodylate buffer ( $\mathrm{pH}$ 7.4) supplemented with a) $100 \mathrm{mM}$ or b) $1,000 \mathrm{mM} \mathrm{KCl}$.

to $30 \mathrm{ng} / \mathrm{\mu l}$. Aliquots $(4 \mathrm{\mu l})$ of template DNA were diluted in reaction solutions $(11 \mu \mathrm{l})$ and incubated at $37^{\circ} \mathrm{C}$ for 2 hr. Fluorescence signals of EGFP were measured using a plate reader (PerkinElmer, Waltham, MA, USA) at $395 \mathrm{~nm}$ excitation and $509 \mathrm{~nm}$ emission wavelengths after diluting the reaction solutions 10 -fold with water.

\section{Results and Discussion}

Using a combination of the empirical G4 motif predictor (QGRS-mapper) [10] and similarity from G4 pattern from G4-microarray and screening [8], we predicted G4-forming sequences. The similarity to known G4 sequences was defined as the distance from the hyperplane calculated using a support vector machine model trained with the G4 microarray results. We then screened both the QGRS mapper-predicted and G4-similar sequences using the fluorogenic 6OTD (6OTD-Np) [9]. 6OTD-Np yields high emission only when bound with G4, not with the other nucleic acid structures, and fluorescence measurement of 6OTD-Np in the presence of G4-forming sequences in SARS-CoV-2 gave two candidates, SC-1 and 2. Then, we validated their G4 formation by IDS analysis, which allows the detection of the characteristic UV absorbance of approximately $295 \mathrm{~nm}$ derived from Hoogsteen hydrogen bonding of G-quartet at $25^{\circ} \mathrm{C}$ using DNA (SC-1 and SC-2) and RNA oligonucleotides (SC-1r and SC-2r) [11]. Since potassium cations stabilize G4, IDS analysis was performed in the presence of $100 \mathrm{mM}$ or $1,000 \mathrm{mM} \mathrm{KCl}$ in lithium cacodylate buffer. As a result, the subtraction of the UV spectra of all oligonucleotides without $\mathrm{KCl}$ (in which no G4 structure was formed due to a lack of potassium cations) from that with 1,000 $\mathrm{mM} \mathrm{KCl}$ yielded peaks around $295 \mathrm{~nm}$, which are characteristic of G4 formation [9]. Even with a lower concentration of $\mathrm{KCl}(100 \mathrm{mM})$, IDS clearly showed a positive peak around $295 \mathrm{~nm}$ (Fig. 2).

To evaluate the influence of the SC-1r and SC-2r G4 on translation, we cloned each sequence and located it upstream of the enhanced green fluorescent protein (EGFP) gene under the regulation of the T7 promoter. We also generated a mutant control in which guanines attributed to G4 were replaced with adenines. The effect of putative G4-forming sequences in SARS-CoV-2 on translation was evaluated by in vitro synthesis of enhanced green fluorescent protein. As a result, the fluorescence signal from SC-2 connected to the EGFP gene (Fig. 3) was clearly reduced compared to that from the SC-2 mutant, which does not form G4. This result suggests that the G4 formation of SC-2r suppressed the 
a)

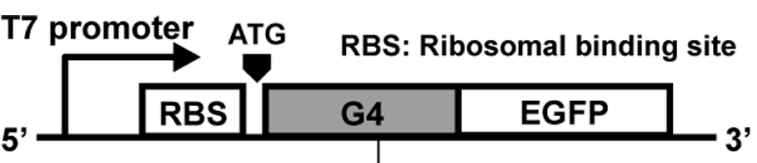

\begin{tabular}{|c|c|}
\hline SC-1 & ATGATAAGGGTATTAAAATACAAGAGGGTGTGGTTGATTATGG TG \\
\hline SC-1 mutant & ATGATAAAAATATTAAAATACAAGAAAATGTGGTTGATTATAA TG \\
\hline SC-2 & ATGGGGTCAGGGTTTAAATGGTTACACTGTAGAGGA \\
\hline SC-2 mutant & ATGAAATCAAAATTTAAATGGTTACACTGTAGAAAA \\
\hline SC-1' & АTGCTATACAGCGTAAATATAAGGGTATTAAAATACAAGAGGGTGTGGTTGATTATGG TG \\
\hline SC-1'mutant & АTGCTATACAGCGTAAATATAAAAATATTAAAATACAAGAAAATGTGGTTGATTATAA TG \\
\hline SC-2' & АTGTATAACCACTTACCCGGGTCAGGGTTTAAATGGTTACACTGTAGAGGA \\
\hline $\begin{array}{l}\text { SC-2' mutant } \\
\text { No G4 }\end{array}$ & $\begin{array}{l}\text { ATGTATAACСАСТTACССАAATCAAAATTTAAATGGTTACACTGTAGAAAA } \\
\text { ATG }\end{array}$ \\
\hline
\end{tabular}

b)

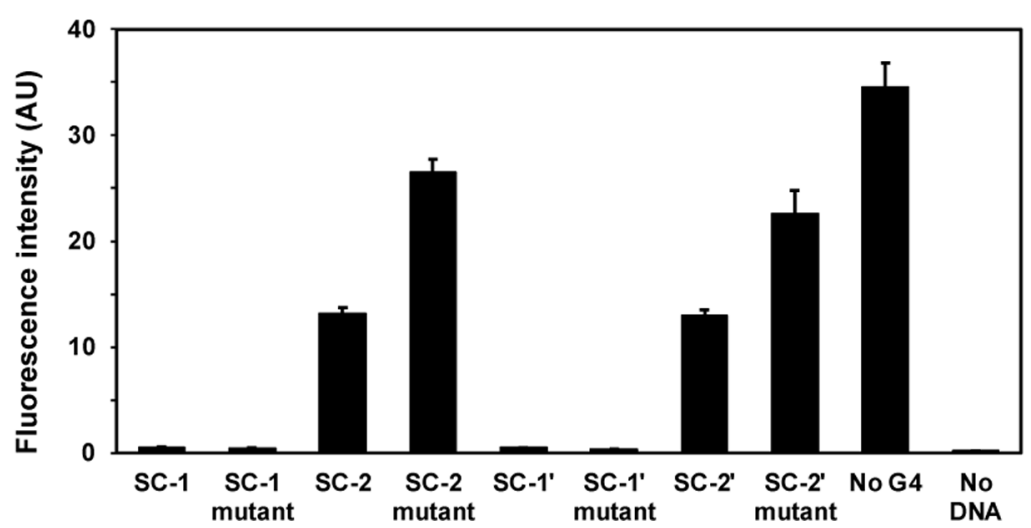

Fig. 3. a) Construction of template DNA containing the putative G4-forming sequences. In each mutant, guanines attributed to G4 were replaced with adenines. b) Fluorescence of synthesized EGFP by co-transcription translation in vitro. Fluorescence was measured at an excitation wavelength of $395 \mathrm{~nm}$ and an emission wavelength of $509 \mathrm{~nm}$. Data are expressed as mean \pm standard deviation. of triplicate experiments.

translation of EGFP. EGFP fluorescence was not observed in either the SC-1 or SC-1 mutant connected EGFR. This might be attributed to the formation of intramolecular hybridization of the mRNAs, since we have identified several potential sites in these transcripts. An alternative reporter protein may be used for further investigation.

All tested RNA sequences of SC- $1 \mathrm{r}$ and SC-2r were found in ORF1a, a region in the SARS-CoV-2 genome (SARS-CoV-2 genomic positions at 4,437 and 4,210), which is known as the ribosomal slippage domain. The ORF1a and $1 \mathrm{~b}$ regions of the SARS-CoV-2 genome are translated as a single, large polyprotein using a ribosomal frameshifting mechanism. The polyprotein is processed into 16 non-structural proteins (nsp). The nsp7, 8, 9, 10, 12, and 14 are assembled as RNAdependent RNA polymerases. Thus, inhibition of ORF1a and $1 \mathrm{~b}$ translation by G4 inhibitors has the potential to suppress the replication of SARS-CoV-2. Since the identified G4-forming sequences are preserved in the SARS-CoV-2 alpha variant (B.1.1.7), these could be promising targets of G4. The G4 formation of SC-2r requires a high concentration of $\mathrm{KCl}$. However, G4 ligands, such as OTDs, markedly stabilize G4 and efficiently inhibit translation. To date, several G4-forming sequences have been reported [12-19], especially in the $\mathrm{N}$ and $\mathrm{S}$ protein-coding regions of SARS$\mathrm{CoV}-2$. However, there are few examples of ORF1a and $b$ G4-forming sequences, since the widely used G4 predictor of the QGRS mapper tends to give high scores to G-rich sequences with equal interval G-tracts. While the present study showed that unevenly distributed G-tracts containing G-rich sequences could also form G4s, the precise rules for forming G4s remain unclear. Visualization of G4 in cells infected with SARS-CoV-2 by fluorogenic G4 ligands [10] would also provide strong evidence for the presence of viral G4. Consequently, anti-viral drug strategies targeting G4s require both a new G4-predicting algorithm and viral G4-selective ligands.

\section{Conclusions}

In this study, we identified two G4-forming sequences in SARS-CoV-2 through a combination of in silico analysis of a G4 predictor, microarray annotation, and fluorogenic G4 screening. Using the IDS analysis, SC-1r and SC-2r were shown to form G4s, and their inhibitory activities towards viral translation are currently under investigation and will be reported in due course.

\section{Conflict of Interest}

There is no conflict of interest to declare.

\section{Acknowledgements}

This research was supported by AMED JP20wm0325016, JSPS/MEXT KAKENHI (JP19K05743, JP21H00275 to M. T. and JP20J13814 to S. S.), and the Inamori Foundation. 


\section{References}

1. Adamson, C. S., Chibale, K., Goss, R. J. M., Jaspars, M., Newman, D. J. and Dorrington, R. A. 2021. Antiviral drug discovery: preparing for the next pandemic. Chem. Soc. Rev. 50: 3647-3655. [Medline] [CrossRef]

2. Zhao, C., Qin, G., Niu, J., Wang, Z., Wang, C., Ren, J. and Qu, X. 2021. Targeting RNA G-quadruplex in SARS-CoV-2: a promising therapeutic target for COVID-19? Angew. Chem. Int. Ed. Engl. 60: 432-438. [Medline] [CrossRef]

3. Butovskaya, E., Heddi, B., Bakalar, B., Richter, S. N. and Phan, A. T. 2018. Major G-quadruplex form of HIV-1 LTR reveals a $(3+1)$ folding topology containing a stem-loop. J. Am. Chem. Soc. 140: 13654-13662. [Medline] [CrossRef]

4. Majee, P., Pattnaik, A., Sahoo, B. R., Shankar, U., Pattnaik, A. K., Kumar, A. and Nayak, D. 2021. Inhibition of Zika virus replication by G-quadruplex-binding ligands. Mol. Ther. Nucleic Acids 23: 691-701. [Medline] [CrossRef]

5. Ruggiero, E. and Richter, S. N. 2020. Viral G-quadruplexes: new frontiers in virus pathogenesis and antiviral therapy. Annu. Rep. Med. Chem. 54: 101-131. [Medline]

6. Iida, K. and Nagasawa, K. 2013. Macrocyclic polyoxazoles as G-quadruplex ligands. Chem. Rec. 13: 539-548. [Medline] [CrossRef]

7. Tera, M., Hirokawa, T., Okabe, S., Sugahara, K., Seimiya, H. and Shimamoto, K. 2015. Design and synthesis of a berberine dimer: a fluorescent ligand with high affinity towards G-quadruplexes. Chemistry 21: 14519-14528. [Medline] [CrossRef]

8. Iida, K., Nakamura, T., Yoshida, W., Tera, M., Nakabayashi, K., Hata, K., Ikebukuro, K. and Nagasawa, K. 2013. Fluorescent-ligand-mediated screening of G-quadruplex structures using a DNA microarray. Angew. Chem. Int. Ed. Engl. 52: 12052-12055. [Medline] [CrossRef]

9. Ma, Y., Wakabayashi, Y., Watatani, N., Saito, R., Hirokawa, T., Tera, M. and Nagasawa, K. 2021. Vinylnaphthalene-bearing hexaoxazole as a fluorescence turn-on type G-quadruplex ligand. Org. Biomol. Chem. 19: 8035-8040. [Medline] [CrossRef]

10. Kikin, O., D'Antonio, L. and Bagga, P. S. 2006. QGRS Mapper: a web-based server for predicting G-quadruplexes in nucleotide sequences. Nucleic Acids Res. 34: W676-82. [Medline] [CrossRef]

11. Gros, J., Aviñó, A., Lopez de la Osa, J., González, C., Lacroix, L., Pérez, A., Orozco, M., Eritja, R. and Mergny, J. L. 2008. 8-Amino guanine accelerates tetramolecular G-quadruplex formation. Chem. Commun. (Camb.) 2926-2928. [Medline] [CrossRef]

12. Bezzi, G., Piga, E. J., Binolfi, A. and Armas, P. 2021. CNBP binds and unfolds in vitro G-quadruplexes formed in the SARS-CoV-2 positive and negative genome strands. Int. J. Mol. Sci. 22: 2614. [Medline] [CrossRef]

13. Ji, D., Juhas, M., Tsang, C. M., Kwok, C. K., Li, Y. and Zhang, Y. 2021. Discovery of G-quadruplex-forming sequences in SARS-CoV-2. Brief. Bioinform. 22: 1150-1160. [Medline] [CrossRef]

14. Cui, H. and Zhang, L. 2020. G-quadruplexes are present in human coronaviruses including SARS-CoV-2. Front. Microbiol. 11: 567317. [Medline] [CrossRef]

15. Belmonte-Reche, E., Serrano-Chacón, I., Gonzalez, C., Gallo, J. and Bañobre-López, M. 2021. Potential G-quadruplexes and i-motifs in the SARS-CoV-2. PLoS One 16: e0250654. [Medline] [CrossRef]

16. Panera, N., Tozzi, A. E. and Alisi, A. 2020. The G-quadruplex/ helicase world as a potential antiviral approach against COVID-19. Drugs 80: 941-946. [Medline] [CrossRef]

17. Zhang, R., Xiao, K., Gu, Y., Liu, H. and Sun, X. 2020. Whole genome identification of potential G-quadruplexes and analysis of the G-quadruplex binding domain for SARSCoV-2. Front. Genet. 11: 587829. [Medline] [CrossRef]

18. Lavigne, M., Helynck, O., Rigolet, P., Boudria-Souilah, R., Nowakowski, M., Baron, B., Brülé, S., Hoos, S., Raynal, B., Guittat, L., Beauvineau, C., Petres, S., Granzhan, A., Guillon, J., Pratviel, G., Teulade-Fichou, M. P., England, P., Mergny, J. L. and Munier-Lehmann, H. 2021. SARS-CoV-2 Nsp3 unique domain SUD interacts with guanine quadruplexes and G4-ligands inhibit this interaction. Nucleic Acids Res. 49: 7695-7712. [Medline] [CrossRef]

19. Xi, H., Juhas, M. and Zhang, Y. 2020. G-quadruplex based biosensor: a potential tool for SARS-CoV-2 detection. Biosens. Bioelectron. 167: 112494. [Medline] [CrossRef] 